\title{
DEFORMATION AND FRACTURE MICROPROCESSES OF EXPLOSIVELY LOADED LOW-CARBON STEELS UNDER TENSION
}

\author{
V.P. LARIONOV (1) and S.P. YAKOVLEVA $(2)$ \\ Oktiabrskaya street 1, Yakutsk 677891, USSR
}

\begin{abstract}
résumé : Les mécanismes à l'origine de la variation de résistance $d^{\prime}$ aciers à faible teneur en carbone soumis à un traitement par explosif sont étudiés à travers les caractéristiques de la déformation plastique et des microprocessus de fracture. On donne une analyse quantitative des caractéristiques de la déformation plastique à l'échelle des inhomogénéités microscopiques.

Abstract - The mechanism of strength properties formation in low-carbon steels subjected to explosive treatment is investigated. With this aim in view, the features inherent to plastic deformation and fracture microprocesses have been studied. A quantitative analysis of the microinhomogeneous plastic deformation characteristics has been carried out.
\end{abstract}

\section{1.- Introduction.}

Three main aspects can be picked out when investigating phenomena occuring during explosive treatment (ET) of metals. The first of them deals with the hydrodynamic material flow and the shock wave theory as applied to solids. The second one addresses the material behavinur during ET. It is closely connected with the third aspect relnoing to material properties analysis after ET. When doing so, it is necessary not only to describe the mechanical propexties but also to study the elementary processes that govern them and determine the mechanisms of plastic deformation and fracture.

\section{2.- Investigation method}

To study the strength nature of materials subjected to ET, we considered the regular and specific features of plastic deformation and their effect on fracture of explosively loaded low-carbon steels under tension/1/. Content of alloying elements in stee 1 was as follows: $0.11 \% \mathrm{C}, 0.42 \% \mathrm{Mn}, 0.3 \% \mathrm{Cr}$, while steel 2 had the following composition: $0.11 \% \mathrm{C}, 0.41 \% \mathrm{Mn}, 0.17 \% \mathrm{Cr}$. During the explosive hardening experiments the material plates had been preliminary annealed to stabilize their structure and then were loaded by a shock wave at $5 \mathrm{GPa}$ according to a sliding detonation method/2/. Tensile tests were conducted on cylin-

(1) Director of the Institute of Physical-Technical Problems of the North, USSR Academy of Sciences.

(2) Senior Researcher in the Institute of Physical-Technical Problems of the North. Laboratory of Metal Surface Treatment. 
drical (steel 1) and flat (steel 2) specimens. Cylindrical specimens were tested in the range from room temperature to $-60^{\circ} \mathrm{C}$. Steel 2 was used for a quantitative analysis of microinhomogeneous plastic strain in flat specimens. The latter tests were carried out in two steps: $4 \%-$ elongation and $5 \ldots 6$ \% -elongation.

The resulting structure was studied by optical and electron microscopy methods. Properties of individual phases and structural components were assessed through microhardness measurements. Owing to the fact that real material properties result from a complex interaction between individual microvolumes of structure, a statistical model of microinhomogeneous medium was used.

Development of plastic deformation in different tension stages was investigated by using a method of reference points that had been marked on flat specimens with the help of the diamond pyramid of a microhardness meter attached to the optical microscope. The number of marks on each specimen reference lines is 100 and 150, the interspacing being of 60 and $20 \mathrm{~m}$, respectively. The following parameters of microstrain inhomogeneity were assessed:

a) strain concentration factor in microregions

$$
\eta=\frac{\varepsilon_{K}}{\bar{\varepsilon}}
$$

where $\mathcal{E}_{k}=\Delta l_{k} / \ell_{0 K}$ is the strain of $k$-th zone in each tension deformation step as a ratio between the interspace increment $\Delta l_{k}$ and the initial interval $\ell_{0 K}$, and $\overline{\mathcal{E}}=\frac{1}{n} \sum_{k=1}^{h} \varepsilon_{k}$ is the average strain along a reference line ( $n$ is the number of microintervals);

b) root-mean-square deviation

$$
\sigma_{\text {rms }}=\sqrt{\frac{1}{n-1} \sum_{k=1}^{n}\left(\varepsilon_{k}-\bar{\varepsilon}\right)^{2}}
$$

c) coefficient of microstrain variation $K=\sigma_{\mathrm{rms}} / \bar{\varepsilon}$ describing the level of microinhomogeneous strain per unit deformation;

d) autocorrelation function $R_{r}$ characterizing the relationship between strains of different microregions and derived from the formula.

$$
R_{r}=\frac{1}{n-r} \sum_{k=1}^{n} x_{k} x_{k+r}, \quad r=0,1,2, \ldots, t,
$$

where $t$ is the maximum number of steps,

$$
x=\frac{\varepsilon_{k}}{\bar{\varepsilon}}-1 \text {. }
$$

3. Effect of ET on deformation microprocesses

As a result of investigating the fine structure of steels before and after explosion loading, it was shown that ET had increased the dislocation density involving a more uniform filling of the ferritic matrix with dislocational structures along with the appearance of twin interlayers.

It should be noted that a simple increase in the total dislocation density does not completely characterize the change of dislocation structure. Formation of physical-mechanical properties depends a lot on distribution and mobility of dislocations. 
Histograms of microhardness distribution in Fig.1 show that ET has diminished the scatter of microhardness values. Average microhardness was $1350 \pm 20 \mathrm{MPa}$ for the original material and $1410 \pm 10 \mathrm{MPa}$ for the treated one. ET had not significantly increased the microhardness but stabilized its values improving the homogeneity of fine structure and, thereby, the strength properties (Fig.2).

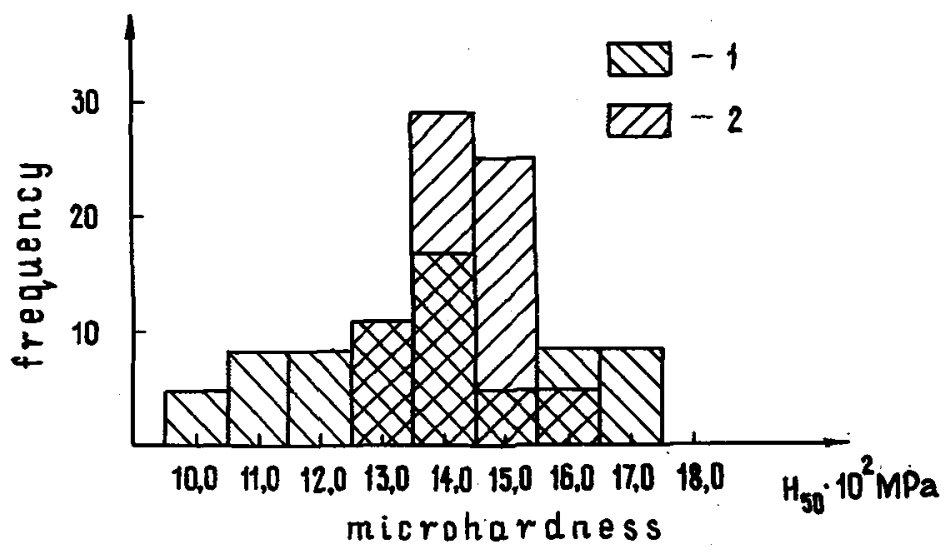

Fig.1.- Histograms of material microhardness distribution before (1) and after ET (2)

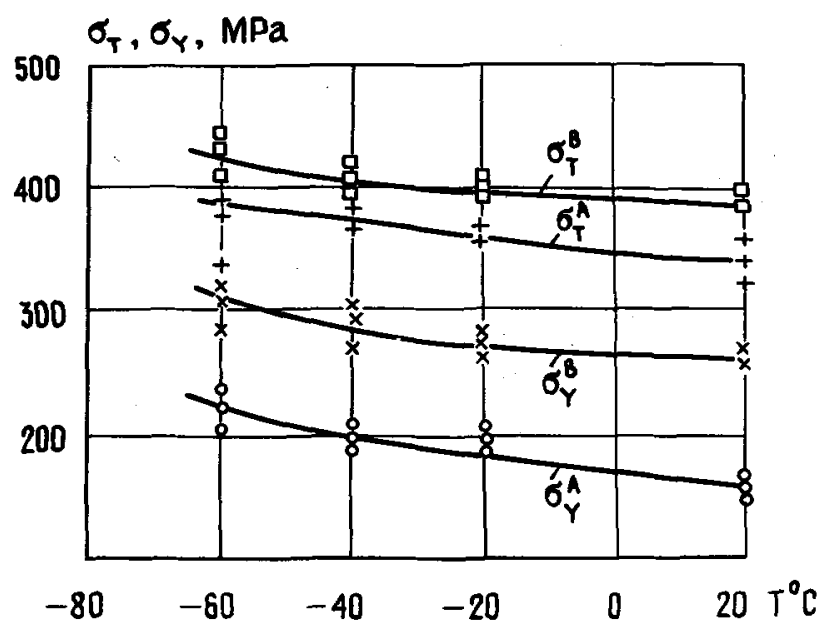

Fig.2.- Strength material characteristics before $\left(\sigma_{Y}^{A}, \sigma_{T}^{A}\right)$ and after $\operatorname{ET}\left(\sigma_{Y}^{B}, \sigma_{T}^{B}\right)$

The fact of substructure homogenization after ET was also evidenced by G.E.Dieter/3/ and W.C.Leslie/4/..

When analysing the distribution of slip traces after static tension, it can be concluded that deformation processes in the material subjected to ET are more uniform and intensive. Indeed, while in the original material only a part of grains is involved in the deformation pro- 
cess, in the treated material the slip traces can be observed practically in all grains (Fig.3). It should be noted here that stress relaxation in the region of twin interlayers occurs through generation of slipping dislocations.

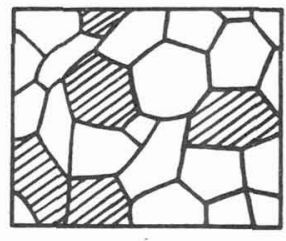

a

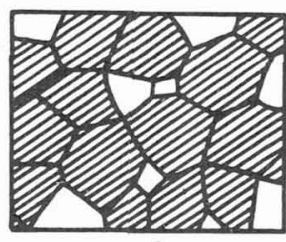

$\mathrm{b}$

Fig.3.- Scheme of material deformation structures before (a) and after ET (b). Hatched are the grains involved in plastic deformation; $\psi=30 \ldots 35 \%$

Deformation of bcc-metals is characterized by a cellular structure formation. An analysis of cellular structures in the necking zone of specimens from the original and the hardened materials showed that ET had allowed for an intensive formation of the strength skeleton in the form of homogeneous cellular structure walls. According to modern concepts, this improves both strength and plasticity. The latter fact is confirmed by plasticity level data: under the given ET and mechanical testing conditions the elongation value of was practically the same while percentage reduction of area $\psi$ even exceeded the initial value. Average values of $\delta$ and $\psi$ for the treated material were 8.7 and $49 \%$ as compared with 11 and $44 \%$ for the original one, which means that the material had improved its ability to withstand the localized plastic strain.

Diagrams of strain concentration factor variation along the reference line with interval of $20 \mu \mathrm{m}$ for two stages of specimen material joading in both states (Fig.4) illustrate the kinetics of microregion deformation initiation.
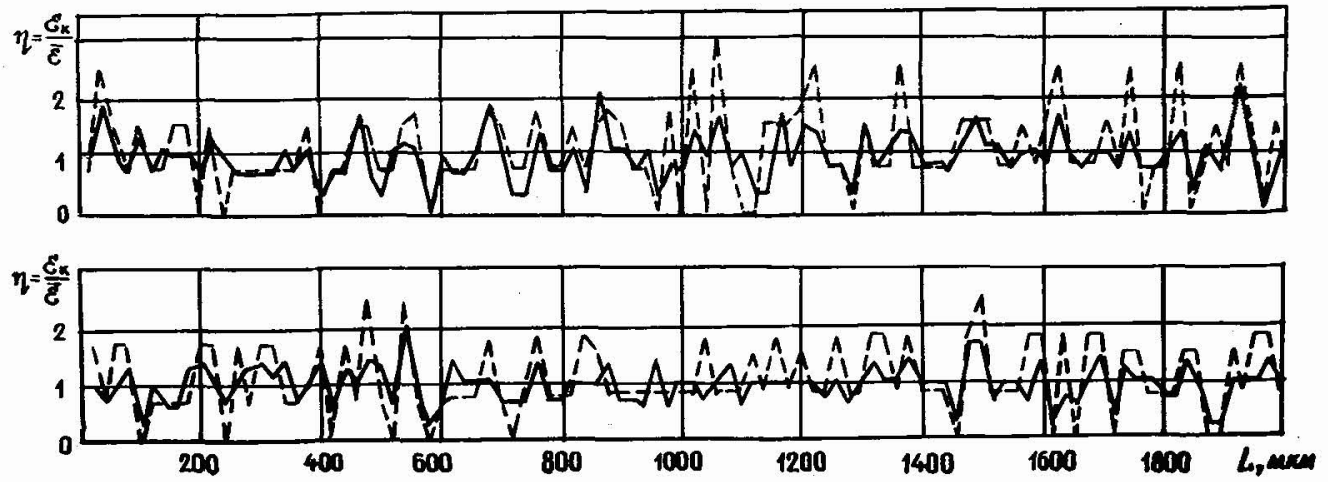

Fig.4.- Microinhomogeneous material strain before (a) and after ET (b) for the first (dashed line) and second (solid line) stages 
As can be seen, the distribution of plastic strain in local regions is not the same. The strain of individual microzones significantly exceeds the average value (ordinate value corresponds to 1 ). There are some regions whose strain is below the average level. In spite of the apparent randomness of microinhomogeneous strain distribution, there is a certain periodicity in alternation of lower and higher strain zones which is due to the material polycrystallinity and impossibility for each individual grain to be deformed independently of each other.

The important role of structural polycrystallinity in the deformation also explains the heredity of strain field pattern observed in the second loading stage. The strain microinhomogeneity developed at the plastic deformation onset and ensuring the material continuity condition is effective in both tension stages leading to formation of fixed lower and higher strain nuclei. This is an important factor that influences the microcrack formation in sites where the ultimate plasticity of individual material microzones is attained.

Substantial differences in the plastic deformation behaviour are observed in the second loading stage when many original material microzones show the further growth of strain inhomogeneity level. On the other hand, the treated material in this stage is characterized by a lowering of inhomogeneity peaks. This confirms the conclusion on higher intensity of microregion local hardening processes that has been derived from the analysis of deformation structures. Specimen elongation up to $10 \%$ is due to the increase of strain levels in other zones thereby showing a trend to the averaging of microstrain levels, i.e. to the delocalization of plastic deformation.

Calculated parameters - root-mean-square deviation and coefficient of microstrain variation $\left(\sigma_{\mathrm{rms}}\right.$ and $\left.K\right)$ represent another evidence of a more homogeneous deformations occuring after ET. The calculations show that the maximum difference in these parameters values was observed in the second tension stage when $\sigma_{\mathrm{rms}}$ of the original material was increased by $25 \%$ and $K$ - by $30 \%$ as compared to the treated material.

An analysis of autocorrelation functions (Fig.5 and 6) makes it possible to assess not only the difference of microinhomogeneous strain levels but also the interaction between microzones with different spacing.
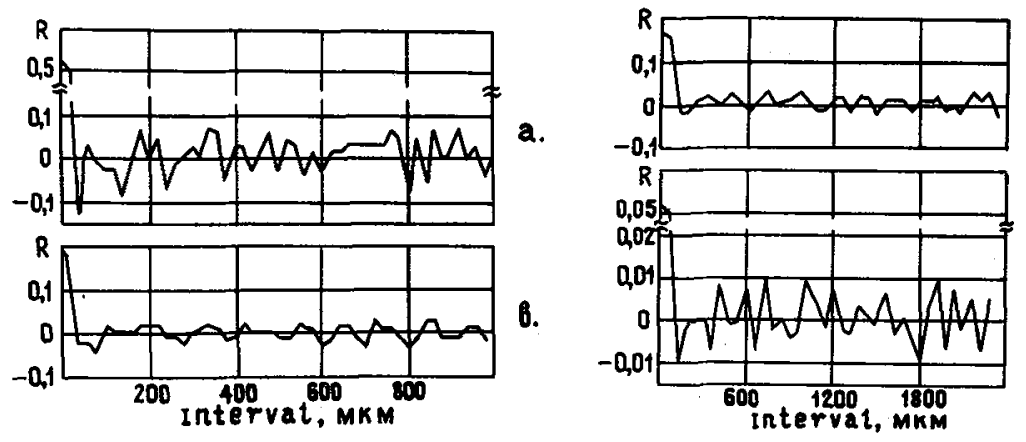

c.

Fig.5.- Autocorrelation functions (ACF) of the original material calculated for the first $(a, c)$ and second $(b, d)$ tension stages; $a, b-$ interval of $20 \mu \mathrm{m}, c, d-$ interval of $60 \mu \mathrm{m}$ 

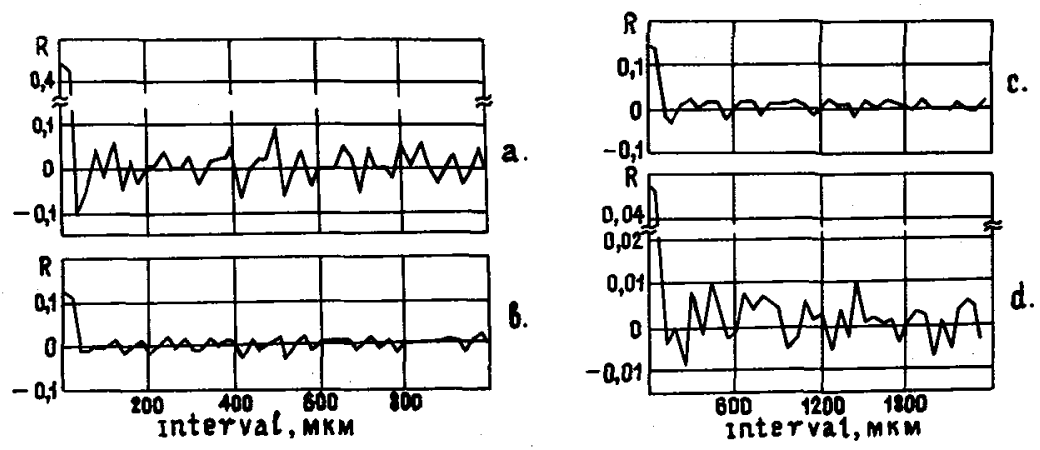

Fig.6.- ACF of the explosively treated material calculated for the first $(a, c)$ and second $(b, d)$ tension stages; $a, b-$ interval of $20 \mu \mathrm{m}, \mathrm{c}, \mathrm{d}$ - interval of $60 \mu \mathrm{m}$

As can be seen, in contrast to the original state, the ordinate values of autocorrelation material functions after ET are lower in both deformation stages and this holds true for both intergranular and interzonal inhomogeneities. Periodicity of ACF is due to the structure polycrystallinity. Its lower amplitudes in the case of treated structure correspond to a lesser reciprocal influence of strained microregions and, therefore, to a weaker interrelation of their strain fields (for the strain levels considered).

The nature of $A C F$ and particularities of microinhomogeneous strain distribution are explained by the decrease of importance of structural inhomogeneities after the shock wave treatment. It is evident that this results from a substructure homogeneity improvement and from its ability to form stable configurations, which diminishes the role 'of casual structural stress concentrators. The same explanation holds true for a relative mutual isolation of strained microregions.

\section{4.- Effect of ET on micromechanisms and kinetics of fracture.}

Fracture sources initiate within a substructure formed by the abovementioned deformation processes, in particular, by void formation. In the original structure the void formation is of different nature resulting in occurence of small and large cavities on fracture surfaces (Fig. 7a). Elements of the cup-and-cone fracture are not so pronounced in the explosively treated material but they are more homogeneous (Fig.7C) since in the hardened matrix the influence of casual structural stress concentrators is diminished while the tensile loading leads to formation of a homogeneous cellular structure. This can restraint the initial void formation, which in accordance with modern concepts improves plasticity. The formation of cellular structure significantly affects the fracture process since the cell boundaries can serve as effective barriers preventing the microcrack propagation. When a microcrack intersects a cell boundary, its growth slows down and, as a result of plastic relaxation, the crack tip blunting occurs. Its further propagation requires an additional energy expenditures because the effective surface energy increases by a value of adjacent zone strain contributing to a more ductile relief formation. Such a fracture mechanism was observed at low temperature tests of the material subjected to ET. 


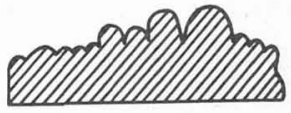

a.

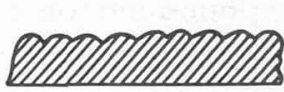

c.

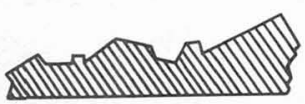

B.

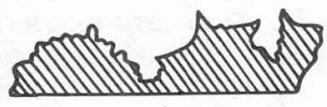

d.

एᄑD - 1 MU -2

Fig.7.- Schematic view of fracture surface microprofiles before $(a, b)$ and after ET $(c, d) ; 1$ - ductile fracture, 2- brittle fracture

The number of slowed microcracks is gradually growing; their coalescence into a critical crack occurs by a quasi-cleavage mechanism with stretching formation (Fig.7d). In the nontreated material the coalescence of microcracks generated at different levels obeys a smooth cleavage mechanism (Fig.7C). And, finally, the cleavage facets of hardened ferrite are characterized by numerous steps whose formation results from elevated energy dissipation during crack propagation through twinned crystals.

Therefore, there is a trend for higher levels of local strain at fracture of explosively treated structure associated with a more complicated fracture surface relief. Thus, we can suggest the higher resistance of explosively treated material to fracture; this is just to explain the increased material ability to withstand the localized strain.

\section{5.- Conclusions}

1. Explosive treatment improves the fine structure homogeneity in lowcarbon steels and contributes to delocalization of plastic deformation processes at subsequent static tension. This impedes the generation of local overstresses involving the early microcracking and subsequent fracture. Under the given experimental conditions and plastic strain level (10\%), the corresponding parameters of microinhomogeneous plastic deformation are improved by $25 \ldots 30 \%$ as compared to original data.

2. The nature of joint deformation occuring in microvolumes of lowcarbon steels subjected to ET creates the conditions for intensive substructural changes leading to formation of a strength skeleton in the form of walls of a fine cellular substructure that is more homogeneous as compared to the original state; this explains the improvement of strength parameters.

3. ET changes the nature of initial microcrack initiation, which influences the whole kinetics of fracture process contributing to a more complicated fracture surface relief and to the growth of local strain level at fracture, and thereby to a greater energy capacity.

4. The observed features of microdeformation and fracture of explosively treated low-carbon steels under the given experimental condi- 
tions resulted in strength increase, the elongation value being decreased only slightly while the parameter of percentage reduction of area even exceeded the initial values.

\section{REFERENCES}

/1/ ЛАРИОНОВ, В.П., ГРИГОРЬЕВ, Р.С. , ЯКОВЛЕВА, С.П., СОВОЛЕНКО, Г.М., ГАВРЙЛЬЕВ, И.Н. ОСОбенности микропроцессов деформации и разрушения малоуглеродистой стали после ударноволновой обработки // Металловед. и терм.обр. металлов (1986).-N12, С.22-24.

/2/ ДЕРИБАС, А.А. Физика упрочнения и сварки взрывом.- Новосибирск: Наука (1980).- $222 \mathrm{c}$.

/3/ DIETER, G.E. Strengthening mechanism in solids.- ASM.- Cleveland (1962) 279 .

/4/ LESLIE, W.C. Microstructural effects of high strain rate deformation / Metallurgical effects at high strain rates. N.Y.;I.: Plenum-Press (1977) 571-586. 